\title{
Estudos Nacionais sobre as Assistências de Enfermagem e de Psicologia ao Idoso Residente em Instituição de Longa Permanência
}

\author{
Andreane Natália Pereira de Almeida Monteiro ${ }^{1}$; Juliane da Silva Pereira² ${ }^{2}$ Mércia Alcântara Feitosa Valença ${ }^{3}$; \\ Maria Amanda Lima Batista ${ }^{4}$; Luciclaudio da Silva Barbosa ${ }^{5}$; Silvana Cavalcanti dos Santos ${ }^{6}$; Ana Carla Silva Alexandre ${ }^{7}$; \\ Claudia Daniele Barros Leite-Salgueiro ${ }^{8}$.
}

\begin{abstract}
Resumo: Este é um estudo de revisão integrativa sobre a produção científica brasileira, englobando a práxis do enfermeiro e do psicólogo na assistência prestada à saúde do idoso residente em Instituição de Longa Permanência para Idosos, que expõe o perfil dos trabalhos publicados em âmbito nacional, no período de 2010 a 2015, indexados nas bases de dados: da Biblioteca Virtual de Saúde (BVS), SciELO, LILACS, Portal Capes e Google Acadêmico. Foram encontrados 47 trabalhos publicados em português. Vinte e sete artigos foram selecionados, sendo a maioria publicada em 2012, em periódicos de enfermagem e gerontologia. A amostra foi apresentada em um quadro com a distribuição dos artigos $(n=27)$, com descrição de indicadores como ano de publicação, título, autor (es), modalidade, área de atuação e objetivos dos artigos selecionados. Os critérios de classificação dos artigos do presente estudo foram descritos por modalidade: artigo de revisão, estudos teóricos e publicação original. Verificou-se ampla discussão na literatura, especialmente com enfoque na assistência prestada pela enfermagem, ao idoso residente em ILPI. Entretanto, escassez de pesquisas nacionais evidenciando as duas atuações profissionais relacionadas na prestação de assistência ao público alvo em questão.
\end{abstract}

Descritores: Envelhecimento; assistência de enfermagem; psicologia; cuidado; ILPI.

\section{National Studies on Nursing and Psychology Assistance to the Elderly Resident in a Long-Stay Institution}

\begin{abstract}
This is an integrative review study on the Brazilian scientific production encompassing the praxis of nurses and psychologists in the care provided to the elderly resident's health in a Long Stay Institution for the Elderly, which presents the profile of the works published in the national context in the period of 2010 to 2015 ,
\end{abstract}

\footnotetext{
${ }^{1}$ Enfermeira formada pelo Instituto Federal de Educação, Ciência e Tecnologia de Pernambuco (IFPE) - Campus Pesqueira. Pesquisadora Colaboradora de Projetos de Pesquisa e Extensão, na linha de Cuidado à Pessoa Idosa, do Instituto Federal de Educação, Ciência e Tecnologia de Pernambuco (IFPE) - Campus Pesqueira. Contato: andreanenathalia@outlook.com .

${ }^{2}$ Enfermeira formada pelo Instituto Federal de Educação, Ciência e Tecnologia de Pernambuco (IFPE) - Campus Pesqueira. Pesquisadora Colaboradora de Projetos de Pesquisa e Extensão, na linha de Cuidado à Pessoa Idosa, do Instituto Federal de Educação, Ciência e Tecnologia de Pernambuco (IFPE) - Campus Pesqueira. Assistente de saúde da Prefeitura Municipal de Pesqueira-Pe. Contato: julianedasilvapereira@gmail.com

${ }^{\mathbf{3}}$ Enfermeira formada pelo Instituto Federal de Educação, Ciência e Tecnologia de Pernambuco (IFPE) - Campus Pesqueira. Contato: merciavalenca123@gmail.com.

${ }^{4}$ Enfermeira formada pelo Instituto Federal de Educação, Ciência e Tecnologia de Pernambuco (IFPE) - Campus Pesqueira. Residente em Saúde da Família /Atenção Básica. Contato: amandalima434@gmail.com .

${ }_{5}^{5}$ Mestre em Recursos Naturais pela Universidade Federal de Campina Grande (UFCG). Biólogo formado pela Universidade Estadual da Paraíba (UEPB). Docente do Curso de Bacharelado em Enfermagem do Instituto Federal de Educação, Ciência e Tecnologia de Pernambuco (IFPE) - Campus Pesqueira. Coordenador dos laboratórios de morfofisiologias dos processos vitais em enfermagem do Instituto Federal de Educação, Ciência e Tecnologia de Pernambuco (IFPE)-Campus Pesqueira. Contato: luciclaudio@pesqueira.ifpe.edu.br.

${ }^{6}$ Mestra em Saúde Pública pelo Centro de Pesquisa Aggeu Magalhaes, Pós Graduada (Lato Sensu) em Saúde Pública pela Associação Caruaruense de Ensino Superior. Enfermeira formada pela Universidade Estadual da Paraíba. Docente do curso Bacharelado em Enfermagem do Instituto Federal de Educação, Ciência e Tecnologia de Pernambuco - Campus Pesqueira. Contato: silvana.santos@pesqueira.ifpe.edu.br . ${ }^{7}$ Doutora em Ciências da Saúde pelo Instituto Universitário Italiano de Rosário, Argentina , Pós Graduada (Lato Sensu) em Unidade de Terapia Intensiva pelo Centro luniversitário Internacional e em Emergência e Urgência (SES). Enfermeira formada pela Faculdade de Enfermagem de Arcoverde (FENFA). Docente do curso Bacharelado em Enfermagem do Instituto Federal de Educação, Ciência e Tecnologia de Pernambuco (IFPE) - Campus Pesqueira. Contato: ana.alexandre@ pesqueira.ifpe.edu.br ;

${ }^{8}$ Doutora em Psicologia Clínica pela Universidade Católica de Pernambuco, Mestra em Ciências da Saúde pela Universidade de Pernambuco (UPE), Pós Graduada (Lato Sensu) em Saúde Coletiva pela mesma Universidade. Psicóloga formada pela Universidade Católica de Pernambuco. Docente do curso Bacharelado em Enfermagem do Instituto Federal de Educação, Ciência e Tecnologia de Pernambuco - Campus Pesqueira. Coordenadora de Projetos de Pesquisa e Extensão, na linha de Cuidado à Pessoa Idosa e em Educação. Contato: claudia.leite@pesqueira.ifpe.edu.br.
} 
indexed in the databases: from the Virtual Health Library (BVS), SciELO, LILACS, Portal Capes and Google Scholar. There were 47 papers published in Portuguese. Twenty-seven papers were selected, most of them being published in 2012 in nursing and gerontology journals. The sample was presented in a table with the distribution of the articles $(n=27)$, with descriptions of indicators such as year of publication, title, author $(s)$, modality, area of work and objectives of selected articles. The classification criteria of the articles of the present study were described by modality: review article, theoretical studies and original publication. There was extensive discussion in the literature, especially with a focus on nursing care provided to the elderly living in ILPI. However, there is a shortage of national surveys evidencing the two related professional activities in the provision of assistance to the target public in question.

Keywords: Aging; nursing care; psychology; care; ILPI.

\section{Introdução}

No mundo e no Brasil, o envelhecimento da população vem se tornando cada vez mais crescente mediante as modificações sociais, econômicas, sanitárias, dentre outras. Evidenciase o aceno para a implementação de novas políticas públicas e serviços de saúde adequados a esse público, e, que visem uma assistência de qualidade ${ }^{1}$.

As indicações numéricas estipulam que em 2020 nosso país estará na sexta colocação em relação ao número de idosos, também, que terá população superior a 30 milhões de pessoas, refletindo assim, numa busca de ações visando uma melhor qualidade de vida ${ }^{2}$. O Instituto Brasileiro de Geografia e Estatística (IBGE) em $2013^{3}$ fez uma previsão de que em 2060 os octogenários representarão $8,75 \%$ da população, sendo a maioria do gênero feminino $(5,37 \%)$.

No Brasil, a população feminina com mais de 60 anos de idade, passou, em 1940, de $2,2 \%$ para $4,7 \%$ no ano 2000 ; e, para $6 \%$ desse extrato populacional como demonstrado em $2010^{4}$ pelo IBGE, este público é o de maior representatividade nas Instituições de Longa Permanência para Idosos (ILPIs). Quanto a variável qualidade de vida, considera-se que viver mais não é sinônimo de viver bem. As mulheres ao longo da vida aglomeram o que alguns estudiosos da saúde consideram enquanto desvantagens, entre estes, são destaques: maior propensão à violência, salários inferiores aos dos homens, discriminação, dupla jornada, solidão pela viuvez, tendo assim a necessidade de uma maior atenção nesta fase da vida ${ }^{5}$.

Enquanto decorrência do alargamento do número de idosos e da longevidade, juntamente com as dificuldades socioeconômicas e culturais envolvendo cuidadores e familiares, assim como também em alguns casos, diante da ausência de um cuidador, tem se tornado crescente a busca pela moradia numa Instituição de Longa Permanência para Idosos $(\mathrm{ILPI})^{2}$. 
Indubitavelmente, a ausência de familiares para o cuidado ou a presença de conflitos familiares, constituem os principais motivos para a institucionalização do idoso, são os conhecidos preditores de ingresso do idoso numa ILPI. De acordo com pesquisa, a permanência neste ambiente pode despertar nos idosos, mais sentimentos negativos do que positivos, podendo prevalecer entre estes sentimentos de solidão, angústia, falta de identidade com o local, menos valia e anseio por sair do asilo ${ }^{6}$.

Em síntese, os principais serviços prestados por profissionais de saúde aos idosos residentes e ILPIs estão relacionados ao/à: acolhimento, humanização, qualidade de vida, autocuidado, individualização. Estes profissionais de saúde são constantemente desafiados a expor sua criatividade e competência atinentes às relações existentes entre o idoso, as normas da instituição, a influência familiar e a adaptação do idoso na realidade da comunidade onde foi inserido $^{7-8}$.

Não obstante, gestores e profissionais das ILPIs têm um grande desafio mediante as modificações próprias do envelhecimento como as doenças já existentes, que poderão agravarse com a institucionalização, podendo incidir numa dependência em diferentes níveis, como a funcional, por exemplo. Diante da situação, é necessário que este idoso seja bem acolhido e tenha sempre suas demandas identificadas, também, que sejam estimuladas por parte da equipe de saúde, principalmente pelo profissional de enfermagem. Pondera-se que este profissional possa ter um bom relacionamento para então desenvolver ações com qualidade, e que visem prevenir patologias e a promoção da saúde ${ }^{9}$.

Diametralmente, postula-se que a ancianidade só será entendida como um ganho para a população longeva, quando melhores condições de vida, aumento da satisfação e do bem-estar ocorrerem e assim, melhorando os indicadores subjetivos e objetivos na busca de vida com qualidade $^{10}$. Talvez, seja justamente pelos motivos acima que, cada vez mais brasileiros com situação econômica diferenciada, buscam os serviços das ILPIs particulares.

O crescente índice populacional de idosos impulsionou o aumento da oferta de Instituições de Longa Permanência para $\operatorname{Idosos}^{12}$ ao longo do território nacional havendo assim, a criação da Resolução da Diretoria Colegiada - RDC no 283, de 26 de setembro de 2005 do Ministério da Saúde ${ }^{13}$, onde foi aprovado o regulamento, determinando as normas para funcionamento adequado destas instituições e garantindo os direitos das pessoas idosas. Também, a portaria 2.528/GM de $2006^{14}$, que dentre as matérias abordadas na política ao público alvo, engloba a promoção do envelhecimento ativo e com qualidade, saúde e manutenção máxima de participação social e da aptidão funcional. 
No Brasil, pondera-se que 0,6\% a 1,3\% da população idosa se encontre em ILPIs, apesar das políticas públicas creditarem às famílias a responsabilidade pelo cuidado ao idoso. A perspectiva é de que haja um aumento na demanda por ILPIs, especialmente, porque alguns idosos, mesmo mantendo sua independência e autonomia, acabam buscando espontaneamente tais instituições para habitar, geralmente por já se considerar com uma participação "abatida" na família ${ }^{15}$.

Ainda considerando-se a população de idosos residentes em ILPIs e destacando-se a nuance de gênero, determinado estudo identificou um número significativo de idosas octogenárias residentes em ILPIs, tal dado acompanha uma tendência mundial. O mesmo estudo revelou que o estado civil estado mais encontrado nessa habitação é a viuvez, o que, somado aos casos de separação e divórcio, representa um número expressivo. O mesmo estudo indicou a presença de muitas idosas sem o cônjuge, mesmo que ele estivesse vivo, também, a necessidade da sociedade, do Estado e a família se engajarem na busca de ações concretas que visem a redução das desigualdades sociais e culturais existentes nas vidas das mulheres idosas, reduzindo sua exposição às situações de risco social ${ }^{16}$.

Os fatores preditores de transferência do idoso do ambiente familiar para uma ILPI são multifatoriais, envolvem desde a própria escolha até mesmo a imposição familiar. As condições de vida e de saúde desses idosos, residentes das ILPI, variam entre a independência, dependência parcial e dependência total para a realização das atividades de vida diária $(\mathrm{AVDs})^{17}$.

Entende-se que ao chegar em uma ILPI, possam haver algumas situações peculiares em relação aos cuidados para com cada integrante do grupo, sendo elas: físicas e/ou emocionais/psicológicas, requerendo da equipe de saúde dessas ILPIs atenção focada individualmente no idoso e mediante as suas necessidades ${ }^{18}$.

Ademais, é necessário que o idoso se adapte às rotinas da ILPI e, aos poucos, é identificado que alguns de seus hábitos domésticos, mantidos durante a vida toda, não poderão continuar mediante as regras da instituição. Essas mudanças, às vezes mesmo que mínimas, poderão provocar mudanças psicossociais e comportamentais que poderão intensificar o isolamento e a inatividade deste idoso ${ }^{19}$.

Considerando-se as doenças prevalentes na velhice, a síndrome da imobilidade e a fragilidade também são preditivos de risco para morte nos longevos e, há causas básicas como: sequelas de traumas e doenças neurológicas, que poderiam ser prevenidas ou ter uma reabilitação precoce, infelizmente, a maioria das ILPIs já se depara com essas condições na admissão, diminuindo, assim, o lócus de ação da equipe multiprofissional nesses lugares para com esse idoso. Outro fator relevante é a idade mais avançada podendo repercutir na perda de 
autonomia pessoal, estes são considerados fatores de risco para mortalidade dos anciãos. Novamente destacando-se a feminização da velhice, observa-se que a maior sobrevida das mulheres justifica estatisticamente a tese de maior número de idosas com idade igual ou superior a 75 anos residentes em ILPIs ${ }^{20}$.

Destarte, mediante promoção de ações que inspiram o autocuidado e resgate da autoestima - atributo indispensável a qualquer pessoa, o foco nestas ações ajuda a emergir / confirmar a sensação de independência do idoso. Entretanto, ocorrendo dependência parcial ou total, há uma grande probabilidade de incidência da perda da sensação de liberdade. Sem dúvida, trata-se de uma sensação extremamente incômoda, pois, passa-se a depender de outros para realizar atividades simples e rotineiras, dentre estas: se alimentar, higienizar-se e deambular, ações que anteriormente eram realizadas com autonomia ${ }^{21}$.

Os idosos relatam que a institucionalização proporciona garantia de acesso aos recursos de saúde. Essa promoção é um fator significativo e essencial principalmente para os longevos. Alguns anciãos relatam essa carência de acompanhamento por apresentarem alguma patologia especifica, sendo essa condição o grande encorajamento para terem ido residir em uma ILPI ${ }^{22}$.

A realização de uma assistência multiprofissional, com destaque para o enfermeiro, que deve lançar mão do conhecimento acerca das características desses idosos para a promoção de um cuidado individualizado, mais efetivo e eficaz, trazendo maiores benefícios ao idoso institucionalizado ${ }^{23}$.

Contextualmente, o enfermeiro como membro atuante na equipe multidisciplinar, deve concretizar a avaliação multidimensional neste idoso, embasada nos princípios da gerontologia, tendo como foco investigar e determinar o estado funcional, a saúde psíquica e a social ${ }^{25}$, para assim ter um sistêmico e integral acompanhamento deste idoso, prestando-lhe uma assistência qualificada, técnica e humanizada.

As funções do profissional de enfermagem na ILPI abrangem: prestar cuidado de ajuda, dar informação que ajudem a minimizar fatores de risco e educação para a saúde. O cuidado em enfermagem é centralizado numa relação dinâmica com o idoso ou a idosa, o enfermeiro deverá auxiliar cada pessoa considerando as suas necessidades individualizadas e aspirações ${ }^{26}$.

Considera-se que a utilização de uma comunicação próxima, própria da enfermagem, e fundamentada num corpo de conhecimento teórico/científico possam proporcionar um maior entendimento, o que consequentemente também oferece benefícios para os idosos, desse modo, ao longo das últimas décadas, enfermeiros no mundo todo têm trabalhado no desenvolvimento e aperfeiçoamento dos termos e sua conceituação ${ }^{27}$.

Pondera-se que os seres humanos carecem de cuidados durante o desenvolver-se até a longevidade, porém, em maior grau na infância e na senilidade. Todos os seres humanos são suscetíveis, condicionados e limitados, esta limitação é decorrente da faze a qual está inserido, 
assim, a perspectiva é que, o cuidado torne-se condição primordial para a sobrevivência, havendo uma influência da cultura para os cuidados de enfermagem em uma ILPI ${ }^{28}$.

A capacitação dos profissionais que irão atuar na área de envelhecimento e saúde do ancião é uma das principais ações da Política Nacional do Idoso no Brasil, justamente, em função do crescente índice de longevidade populacional do país ${ }^{29}$.

O psicólogo dentro da instituição geriátrica é um profissional de grande importância para o idoso que ali reside, uma vez que pode propiciar a expansão de melhores condições e rearranjos como autonomia, independência, aumento da autoestima dos idosos, participação social, dentre outras questões. Impulsionando a conservação de um estilo de vida saudável, podendo reduzir a chance de episódio de doenças. Além de avigorar as soluções do próprio indivíduo para a preservação da saúde psíquica e integral. Também, estimula sua participação em atividades educacionais e sociais, a troca de apoio social, a concepção de novos interesses e o estabelecimento de vínculos afetivos entre os usuários da ILPI. Apoia ainda o engajamento em atividades que possam estimular a criatividade, a sociabilidade e a participação social/comunitária, cooperando para a efetivação de metas pessoais dos idosos e dando um sentido pessoal, maior à vida ${ }^{30}$.

Destarte, tornam-se favoráveis modificações para que ocorra uma gestão com qualidade, uma assistência ao idoso de maneira adequada, dentro das leis que regem as ILPIs e necessárias aos cuidados prestados a este público ${ }^{31}$.

Para que o profissional capacitado e atuante na área da saúde possa atender às necessidades de saúde do idoso, o mesmo deve ter sensibilidade para compreender o idoso em seu contexto sociocultural, também, de fortalecer a responsabilidade e o entendimento de sua condição - que pode trazer algumas limitações - uma vez que, assim como seu potencial para uma ação, ocorrem mediante a etapa de vida na qual está. Em outras palavras, fica a tônica do grande desafio da sociedade para este milênio, isto é, construir uma consciência coletiva de forma que a sociedade seja igualitária para todas as idades, com justiça e garantia plena de direitos para todos e todas ${ }^{32}$.

O cuidado com a saúde dos idosos residentes em uma ILPI não se cumpre exclusivamente alicerçado em bases técnico cientificas, mas, também, levando-se em consideração seus conhecimentos, suas crenças, sua cultura, suas experiências de vida. $\mathrm{O}$ enfermeiro tende a prestar um cuidado qualificado em sua assistência a este idoso quando busca parcerias no atendimento de multiprofissionais existentes na instituição, vencendo assim as 
barreiras como: audição, visão, mobilidade e comunicação diminuída dessas idosas, igualmente, criando estratégias para tornar o atendimento satisfatório ${ }^{33}$.

A formação educacional dos profissionais que atuam em ILPIs vem sendo amplamente debatida, principalmente considerando-se os cuidados necessários com os idosos que não podem ser realizados, senão minimamente, com implicação nas seguintes características profissionais observadas: técnica, de conhecimentos específicos, mediante princípios éticos e $\mathrm{fé}^{34}$.

Deste modo, o presente estudo objetivou verificar a práxis do enfermeiro e do psicólogo na assistência prestada à saúde do idoso residente em uma Instituição de Longa Permanência para Idosos (ILPI) através de rigorosa revisão integrativa da literatura.

\section{Metodologia}

Trata-se de um estudo revisão integrativa da literatura, alusivo à produção do conhecimento sobre a práxis do enfermeiro e do psicólogo, na assistência à saúde do idoso residente em Instituição de Longa Permanência para Idosos (ILPI).

Tal método de pesquisa oportuniza o julgamento de pesquisas científicas de maneira sistemática e ampliada, favorece também a caracterização e a divulgação do conhecimento produzido $^{11}$. Além disso, propicia um sumário da conjuntura do conhecimento de um dado tema, conhecido também como "estado da arte", possibilitando a identificação do lapso que há na informação, sendo necessária a realização de novas pesquisas ${ }^{11}$. O método defende a síntese de vários estudos publicados e permite sinalizações gerais a respeito de uma área particular em estudo $^{11}$.

Esta modalidade de pesquisa é norteada por uma trajetória metodológica composta por seis fases distintas, a saber: 1-estabelecimento do problema da revisão (elaboração da pergunta norteadora, 2-estabelecimento de descritores em saúde e dos critérios para inclusão/exclusão de artigos); 3-amostragem (seleção dos artigos); 4-categorização do estudo; 5-definição dos elementos a serem extraídos dos trabalhos revisados, análise e 6-discussão acerca das tecnologias utilizadas/desenvolvidas e síntese da informação evidenciada nos artigos avaliados ou apresentação da revisão integrativa ${ }^{11}$.

Com o intuito de sistematizar a revisão integrativa, primeiramente, for identificado o tema de interesse, e a pesquisa foi direcionada partindo da seguinte questão norteadora: Qual a 
Assistência do Enfermeiro e do Psicólogo à Saúde do Idoso residente em ILPI difundida em periódicos online, no período de 2010 a 2015 ?

Para especificar as publicações que compuseram a revisão integrativa deste estudo, realizou-se uma busca online, com o levantamento a partir da base de dados da Biblioteca Virtual de Saúde (BVS), com direcionamento para: a Scientific Electronic Library Online SciELO, a Literatura Latino-Americana e do Caribe em Ciências da Saúde - LILACS, Portal Capes e Google Acadêmico, nos meses de março e abril de 2016. Para isso, foram empregados os seguintes descritores em Ciências da Saúde (DeCS): envelhecimento, assistência de enfermagem, psicologia, cuidado e ILPI.

A busca inicial, considerando-se os descritores conjuntamente, constituiu-se de 47 publicações pertinentes à temática investigada, todas disponibilizadas em periódicos online, das quais, 27 artigos constituíram o universo amostral cuidadosamente selecionado considerandose reflexões acerca dos elementos estruturantes dos artigos lidos, também, tendo em vista os critérios de inclusão previamente definidos: artigos científicos publicados em português, completamente disponibilizados online, no período de 2010 a 2015, nas modalidades artigo científico original, estudo teórico e estudos de revisão. Em relação aos critérios de exclusão, levaram-se em conta: artigos sem resumo ou em duplicidade, publicados em idiomas estrangeiros, teses, ou que estivessem fora do período determinado, e os que não se aproximavam da temática sugerida.

Haja vista o juízo para categorização dos artigos do presente estudo, a modalidade "revisão" foi avaliada enquanto uma pesquisa realizada mediante material previamente analisado. Foram considerados "estudos teóricos", aqueles que apresentavam conceitos ou teorias. Foi julgada publicação “original”, aquela que apresentou resultados conclusivos.

A fim de instrumentalizar a coleta dos dados, foi elaborado um quadro contendo as seguintes informações, a saber: título, autor (es), ano de publicação, modalidade, área de atuação dos pesquisadores e objetivos.

\section{Resultados}

O presente estudo constituiu-se de 27 publicações sobre a práxis do enfermeiro e do psicólogo na assistência à saúde do idoso residente em ILPI, tanto na caracterização quanto na categorização. Quanto aos anos de publicação, foi identificado que no ano de 2012 houve um 
número maior de estudos publicados, contemplando oito artigos (29,6\%); seguido de 2014, com sete $(25,9 \%)$ publicações; depois, o ano de 2013, com quatro estudos (14,8\%); subsequentemente, o ano de 2011, com três estudos $(11,1 \%)$ publicações; seguido pelo ano de 2015, com três (11,1\%); e, por fim, 2010, com dois estudos $(7,4 \%)$.

A modalidade artigo científico original foi observada no quantitativo de vinte e cinco publicações $(92,6 \%)$, a modalidade estudos de revisão não obteve representatividade, uma vez que, não foram encontrados estudos na área, a modalidade estudo teórico representou dois artigos $(7,4 \%)$ do total de publicações.

Em relação às áreas de conhecimento, sobressaíram-se as de Enfermagem com 15 (55,5\%) publicações, seguida de Gerontologia, com cinco (18,5\%) publicações. Já as áreas de Psicologia e Multidisciplinar representaram o universo amostral de duas publicações $(7,4 \%)$ totalizando o quantitativo de (14,8\%). Por fim, as áreas de Medicina, Serviço Social e Economia Doméstica; Saúde Coletiva e áreas de afins representaram o universo amostral de uma publicação $(3,7 \%)$, respectivamente, representando o total de $(11,1 \%)$.

Mediante a pesquisa realizada, foi demonstrado que o ano com maior porcentagem de publicações, foi 2012 (29,6\%), onde os estudos pela classe de enfermagem foram mais explorados (55,5\%), também fica evidenciado que, cada vez mais, a longevidade e sua discussão estão em ascensão no Brasil.

A modalidade com maior porcentagem em termos de publicação foi artigos originais $(92,6 \%)$, nos mesmos ficou evidenciada a ocorrência de pesquisas completas, com uma abrangência ampla do tema estudado, além disto, com resultados e discussão presentes nestes estudos.

O quadro 1 descreve a distribuição dos artigos atualizados que trouxeram maior robustez para o estudo, segundo: numeração e ano de publicação (de forma descrente), título, autor (es), modalidade, área de atuação e objetivos. 
Quadro1. Distribuição dos artigos (n=27), segundo ano, título, autor (es), modalidade, área de atuação e objetivos das publicações selecionadas para o estudo.

\begin{tabular}{|c|c|c|c|c|c|}
\hline $\begin{array}{l}\text { Numeração } \\
\text { e Ano }\end{array}$ & Título & Autor (es) & Modalidade & $\begin{array}{l}\text { Área de } \\
\text { atuação }\end{array}$ & Objetivos \\
\hline 2010 & $\begin{array}{lccc}\text { Cuidado } & \text { sistematizado } & \text { a idosos } & \text { com } \\
\text { afecção } & \text { Demencial, } & \text { residentes } & \text { em } \\
\text { instituição de longa permanência. } & \end{array}$ & $\begin{array}{l}\text { Isac Silva de Jesus ; Edite Lago da Silva } \\
\text { Sena ; Edméia Campos Meira; } \\
\text { Lucia Hisako Takase Gonçalves; Angela } \\
\text { Maria Alvarez. }\end{array}$ & $\begin{array}{l}\text { Artigo } \\
\text { Original }\end{array}$ & Enfermagem & $\begin{array}{l}\text { Sistematizar um modelo básico de cuidados de enfermagem } \\
\text { baseado na taxonomia da North } \\
\text { American Nursing Diagnosis Association (NANDA), testado } \\
\text { em idosos com afecção demencial, residentes em instituição } \\
\text { De longa permanência (ILPI), no interior baiano. }\end{array}$ \\
\hline 2010 & $\begin{array}{l}\text { Cuidados aos idosos institucionalizados - } \\
\text { opiniões do sujeito } \\
\text { Coletivo enfermeiro para } 2026 \text {. }\end{array}$ & $\begin{array}{l}\text { Bárbara Tarouco da Silva; Silvana } \\
\text { Sidney Costa Santos. }\end{array}$ & Artigo Original & Enfermagem & $\begin{array}{l}\text { Identificar a percepção de enfermeiros a respeito do cuidado } \\
\text { de enfermagem direcionados às pessoas idosas residentes em } \\
\text { Instituição de Longa Permanência para Idosos. }\end{array}$ \\
\hline $\begin{array}{l}3- \\
2011\end{array}$ & Óbitos em instituição asilar. & $\begin{array}{l}\text { Milton Luiz Gorzoni; Sueli Luciano } \\
\text { Pires. }\end{array}$ & Artigo original & Medicina & $\begin{array}{l}\text { Definir as causas de morte em população internada em } \\
\text { instituição de longa } \\
\text { Permanência para idosos (ILPI). }\end{array}$ \\
\hline 2011 & $\begin{array}{l}\text { Projeto saúde do idoso institucionalizado } \\
\text { Atuação dos profissionais na atenção à } \\
\text { saúde de } \\
\text { Idosos residentes em instituição de longa } \\
\text { Permanência. }\end{array}$ & $\begin{array}{l}\text { Marcia Denise Moreira Rocha; } \\
\text { Maria Celina da Piedade Ribeiro. }\end{array}$ & Artigo original & Multidisciplinar & $\begin{array}{l}\text { Promover saúde e bem-estar, para que } \\
\text { os idosos se sintam estimulados a viver } \\
\text { com prazer. }\end{array}$ \\
\hline 2011 & $\begin{array}{l}\text { Senescência e senilidade: novo paradigma } \\
\text { na } \\
\text { Atenção Básica de Saúde. }\end{array}$ & $\begin{array}{l}\text { Suely Itsuko Ciosak; Elizabeth Braz; } \\
\text { Maria Fernanda Baeta Neves A. Costa; } \\
\text { Nelize Gonçalves } \\
\text { Rosa Nakano; Juliana Rodrigues; Rubia } \\
\text { Aguiar Alencar; Ana Carolina A. } \\
\text { Leandro da Rocha. }\end{array}$ & Estudo teórico & Enfermagem & $\begin{array}{l}\text { Conhecer o cotidiano dos idosos que é um desafio para os } \\
\text { profissionais } \\
\text { de saúde para implementar programas e } \\
\text { ações que visem alcançar a manutenção do equilíbrio no } \\
\text { processo saúde-doença. }\end{array}$ \\
\hline 2012 & $\begin{array}{l}\text { Déficits de autocuidado de idosas } \\
\text { institucionalizadas. }\end{array}$ & $\begin{array}{l}\text { Natasha Marques Frota; Zélia Maria de } \\
\text { Sousa Araújo Santos; Enedina Soares; } \\
\text { Jaydê Moraes Gonçalves de Moura; } \\
\text { Andréa de Carvalho Costa; Joselany Âfio } \\
\text { Caetano. }\end{array}$ & Artigo original & Enfermagem & $\begin{array}{l}\text { Identificar os déficits de autocuidado de idosas } \\
\text { institucionalizadas. }\end{array}$ \\
\hline 7- & $\begin{array}{l}\text { Experiências vivenciadas por acadêmicos } \\
\text { de enfermagem com idosos }\end{array}$ & $\begin{array}{l}\text { Bárbara Coeli Oliveira da Silva; } \\
\text { Gysella Rose Prado de Carvalho; } \\
\text { Isaiane da Silva Carvalho; }\end{array}$ & Artigo Original & Gerontologia & $\begin{array}{l}\text { Relatar a experiência acadêmica de alunos de graduação em } \\
\text { enfermagem, vivenciada na observação das diferenças entre } \\
\text { idosos ativos que participavam de um Grupo de Terceira }\end{array}$ \\
\hline
\end{tabular}




\begin{tabular}{|c|c|c|c|c|c|}
\hline 2012 & $\begin{array}{l}\text { institucionalizados } \\
\text { institucionalizados. }\end{array}$ & $\begin{array}{l}\text { Alcides Viana de Lima Neto; } \\
\text { Vilani Medeiros de Araújo Nunes; } \\
\text { Rosineide Dantas Torres de Araújo. }\end{array}$ & & & $\begin{array}{l}\text { Idade e idosos residentes numa Instituição de Longa } \\
\text { Permanência. }\end{array}$ \\
\hline 2012 & $\begin{array}{l}\text { Mulher idosa: vivências do processo } \\
\text { De institucionalização. }\end{array}$ & $\begin{array}{l}\text { Inayara Oliveira de Santana; Maria da } \\
\text { Penha de Lima Coutinho; Natália Ramos; } \\
\text { Deraci Souza dos Santos; Gilcínila Laís } \\
\text { Cardoso Lemos; Paloma Borges Silva. }\end{array}$ & Artigo Original & Multidisciplinar & $\begin{array}{l}\text { Investigar aspectos psicossociais do processo de } \\
\text { institucionalização } \\
\text { de mulheres idosas na cidade de Santo Antônio de Jesus- } \\
\text { Bahia-Brasil. }\end{array}$ \\
\hline $9-2012$ & $\begin{array}{l}\mathrm{O} \text { enfermeiro e o cuidado à mulher idosa: } \\
\text { abordagem da fenomenologia social. }\end{array}$ & $\begin{array}{l}\text { Sebastião Caldeira; } \\
\text { Miriam Aparecida Barbosa Merighi; } \\
\text { Luz Angelica Muñoz; } \\
\text { Maria Cristina Pinto de Jesus; } \\
\text { Selisvane Ribeiro da Fonseca Domingos; } \\
\text { Deíse Moura de Oliveira. }\end{array}$ & Artigo Original & Enfermagem & $\begin{array}{l}\text { Compreender a ação de cuidar da mulher idosa, sob a } \\
\text { perspectiva do enfermeiro. }\end{array}$ \\
\hline 2012 & $\begin{array}{l}\text { Sentimentos de residir em uma instituição } \\
\text { de longa } \\
\text { Permanência: percepção de idosos asilados. }\end{array}$ & $\begin{array}{l}\text { Leidyani Karina Rissardo; } \\
\text { Mara Cristina Ribeiro Furlan; } \\
\text { Graciella GrandizolliI; } \\
\text { Sonia Silva Marcon; } \\
\text { Lígia Carreira. }\end{array}$ & $\begin{array}{l}\text { Artigo } \\
\text { Original }\end{array}$ & Enfermagem & $\begin{array}{l}\text { Conhecer a percepção do } \\
\text { Idoso sobre os motivos que levaram à sua institucionalização, } \\
\text { bem como seus sentimentos diante desta condição. }\end{array}$ \\
\hline 2012 & $\begin{array}{l}\text { Significado atribuído pelos idosos à } \\
\text { vivência em uma } \\
\text { Instituição de longa permanência: } \\
\text { contribuições para o } \\
\text { Cuidado de enfermagem. }\end{array}$ & $\begin{array}{l}\text { Tatiane Michel; Maria Helena Lenardt; } \\
\text { Susanne Elero Betiolli; Dâmarys } \\
\text { Kohlbeck de Melo Neu. }\end{array}$ & Artigo Original & Enfermagem & $\begin{array}{l}\text { Interpretar o significado atribuído pelos idosos à vivência em } \\
\text { uma Institução } \\
\text { De Longa Permanência para Idosos, do município de } \\
\text { Curitiba, Paraná. }\end{array}$ \\
\hline 2012 & $\begin{array}{l}\text { Equipe multidisciplinar: essencial para o } \\
\text { cuidado dos idosos em instituição de longa } \\
\text { permanência. }\end{array}$ & $\begin{array}{l}\text { Juliana Cassiano Lemos; Jacqueline } \\
\text { Damasceno de Castro barros. }\end{array}$ & Artigo Original & Enfermagem & $\begin{array}{l}\text { Identificar a importância da Equipe Multidisciplinar junto as } \\
\text { Instituições de Longa Permanência para Idosos. }\end{array}$ \\
\hline 2012 & $\begin{array}{l}\text { Percepção de idosos sobre o papel do } \\
\text { Psicólogo em Instituições de } \\
\text { Longa Permanência. }\end{array}$ & $\begin{array}{l}\text { Jimilly Caputo Corrêa; } \\
\text { Maria Elisa Caputo Ferreira; } \\
\text { Vanessa Nolasco Ferreira; } \\
\text { Eliane Ferreira Carvalho Banhato. }\end{array}$ & Artigo Original & Psicologia & $\begin{array}{l}\text { Descrever a percepção de idosos institucionalizados } \\
\text { sobre o papel do profissional psicólogo junto à população } \\
\text { abrigada nas Instituições de Longa Permanência para Idosos } \\
\text { (ILPI) da cidade de Juiz de Fora- } \\
\text { MG. }\end{array}$ \\
\hline 14- & $\begin{array}{l}\text { A imobilidade em Instituição de Longa } \\
\text { Permanência: Compreendendo o desafio } \\
\text { vivenciado pelas equipes de saúde. }\end{array}$ & $\begin{array}{l}\text { Ariane Rubin Cocco; Ana Paula } \\
\text { Naspolini; Fabrício Pontes Grando; } \\
\text { Noêmia Volgoi; Ezequiel da Silva; Paulo }\end{array}$ & Artigo Original & Gerontologia & $\begin{array}{l}\text { Identificar as variáveis associadas à imobilidade e à } \\
\text { realização das atividades básicas da vida diária (AVDs) em } \\
\text { uma Instituição de Longa Permanência (ILPI). }\end{array}$ \\
\hline
\end{tabular}




\begin{tabular}{|c|c|c|c|c|c|}
\hline 2013 & & $\begin{array}{l}\text { Adão de Medeiros; Melissa Agostini } \\
\text { Lampert. }\end{array}$ & & & \\
\hline $\begin{array}{l}15- \\
2013\end{array}$ & $\begin{array}{l}\text { O Idoso residente em ILPI (Instituição de } \\
\text { Longa Permanência do Idoso) e o que isso } \\
\text { representa para o sujeito idoso. }\end{array}$ & $\begin{array}{l}\text { Maria Carla N. S. Costa; } \\
\text { Elizabeth Frohlich Mercadante. }\end{array}$ & Estudo teórico & Gerontologia & $\begin{array}{l}\text { Discutir a velhice abrigada em moradia coletiva, } \\
\text { fundamentalmente a do idoso residente em ILPI, e o que } \\
\text { representa para esse sujeito o fato de residir nesse tipo de } \\
\text { instituiçãa. }\end{array}$ \\
\hline 2013 & $\begin{array}{l}\text { Prestar cuidados de enfermagem a pessoas } \\
\text { idosas: experiências e impactos. }\end{array}$ & Liliana Sousa; António Pedro Ribeiro. & Artigo Original & $\begin{array}{l}\text { Saúde Pública/Cole- } \\
\text { tiva e de áreas afins }\end{array}$ & $\begin{array}{l}\text { Contribuir para compreender melhor os desafios dos } \\
\text { enfermeiros no cuidado à pessoa idosa, promovendo } \\
\text { cuidados de maior qualidade num cenário de envelhecimento } \\
\text { populacional. }\end{array}$ \\
\hline 2013 & $\begin{array}{l}\text { Idosos em Instituições de Longa } \\
\text { Permanência: } \\
\text { Desenvolvimento, Condições de Vida e } \\
\text { Saúde. }\end{array}$ & $\begin{array}{l}\text { Júnia Denise Alves-Silva; Fabio } \\
\text { Scorsolini-Comin e Manoel Antônio dos } \\
\text { Santos. }\end{array}$ & Artigo Original & Psicologia & $\begin{array}{l}\text { Realizar uma revisão integrativa da literatura científica a } \\
\text { respeito dos fatores que levam os idosos a se transferirem de } \\
\text { seu ambiente familiar para instituiçôes de longa permanência } \\
\text { para idosos (ILPI), assim como suas condições de vida e } \\
\text { saúde. }\end{array}$ \\
\hline $\begin{array}{l}18- \\
2014\end{array}$ & $\begin{array}{l}\text { A percepção dos graduandos de } \\
\text { enfermagem sobre envelhecimento. }\end{array}$ & $\begin{array}{l}\text { Ana Luiza Barreto de Oliveira; Mavy } \\
\text { Batista Dourado; Tânia Maria Oliva de } \\
\text { Menezes. }\end{array}$ & Artigo Original & Enfermagem & $\begin{array}{l}\text { Analisar a percepção dos graduandos de enfermagem sobre o } \\
\text { envelhecimento. }\end{array}$ \\
\hline 2014 & $\begin{array}{l}\text { Condições de saúde de idosos residentes em } \\
\text { Instituição de Longa } \\
\text { Permanência segundo necessidades } \\
\text { humanas básicas. }\end{array}$ & $\begin{array}{l}\text { Paula Beatriz de Oliveira; Darlene Mara } \\
\text { dos Santos Tavares. }\end{array}$ & Artigo Original & Enfermagem & $\begin{array}{l}\text { Caracterizar os idosos residentes em Instituições de Longa } \\
\text { Permanência (ILPI) segundo as variáveis: } \\
\text { Sexo, idade, escolaridade, causa de admissão e tempo de } \\
\text { permanência; e descrever suas condições de saúde segundo a } \\
\text { teoria } \\
\text { das necessidades humanas básicas. }\end{array}$ \\
\hline 2014 & $\begin{array}{l}\text { Habilidades de resolução de problemas e } \\
\text { Indicadores de bem-estar emocional em } \\
\text { Profissionais de enfermagem que atuam em } \\
\text { Instituições de Longa Permanência para } \\
\text { Idosos. }\end{array}$ & $\begin{array}{l}\text { Ahlam Ghandour; } \\
\text { Ricardo da Costa Padovani; } \\
\text { Samila Sathler Tavares Batistoni. }\end{array}$ & Artigo Original & Gerontologia & $\begin{array}{l}\text { Identificar habilidades de resolução de problemas e } \\
\text { Indicadores de estresse e ansiedade em profissionais que } \\
\text { compõem equipes de enfermagem que } \\
\text { Atuam em Instituições de Longa Permanência para Idosos } \\
\text { (ILPI's). }\end{array}$ \\
\hline 2014 & $\begin{array}{l}\text { Idosos residentes em uma instituição de } \\
\text { longa permanência: } \\
\text { Adaptação à luz de Callista Roy. }\end{array}$ & $\begin{array}{l}\text { Maria Célia de Freitas; Maria Vilani } \\
\text { Cavalcante Guedes; Francisca Tereza de } \\
\text { Galiza; } \\
\text { Jéssica de Menezes Nogueira; Marília } \\
\text { Ribeiro Onofre. }\end{array}$ & Artigo Original & Enfermagem & $\begin{array}{l}\text { Avaliar o processo de adapta..o de idosos que buscam, } \\
\text { voluntariamente, residir em Instituto de Longa } \\
\text { Permanência para Idosos (ILPI), na cidade de Fortaleza-CE, } \\
\text { com base no modelo teórico de Roy. }\end{array}$ \\
\hline
\end{tabular}




\begin{tabular}{|c|c|c|c|c|c|}
\hline 2014 & $\begin{array}{l}\text { Instituição de longa permanência para } \\
\text { idosos: } \\
\text { Um lugar de cuidado para quem não tem } \\
\text { opção? }\end{array}$ & $\begin{array}{l}\text { Janine Melo de Oliveira; Célia Alves } \\
\text { Rozendo. }\end{array}$ & Artigo Original & Enfermagem & $\begin{array}{l}\text { Compreender o significado da instituição } \\
\text { De longa permanência para idosos institucionalizados. }\end{array}$ \\
\hline 2014 & $\begin{array}{l}\text { Perfil dos colaboradores de uma } \\
\text { Instituição de Longa Permanência para } \\
\text { Idosos (ILPI). }\end{array}$ & $\begin{array}{l}\text { Claudia Lysia de Oliveira Araújo; } \\
\text { Cleny Maciel Lopes; } \\
\text { Gleiciane Rosa Santos; } \\
\text { Luana Pires Junqueira. }\end{array}$ & Artigo Original & Gerontologia & $\begin{array}{l}\text { Delinear um perfil dos colaboradores que trabalham em } \\
\text { ILPI's em quatro municípios do Vale do Paraíba. }\end{array}$ \\
\hline 24- & $\begin{array}{l}\text { Pessoa idosa: capacidade funcional para as } \\
\text { atividades básicas e instrumentais da vida } \\
\text { diária. }\end{array}$ & $\begin{array}{l}\text { Leticia Silveira Cardoso; Barbara } \\
\text { Tarouco da Silva; Daine dos } \\
\text { Rodrigues; Cristiana Lopes } \\
\text { Marcelo Clarete Seracini Penner. }\end{array}$ & Artigo Original & Enfermagem & $\begin{array}{l}\text { Avaliar a capacidade funcional de pessoas idosas residentes } \\
\text { em instituições de longa permanência de um município da } \\
\text { região da campanha/RS. }\end{array}$ \\
\hline 25- & 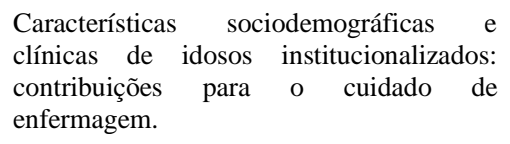 & $\begin{array}{l}\text { Cíntia Lira Borges; Maria Josefina da } \\
\text { Silva; Jorge Wilker Bezerra Clares; } \\
\text { Jéssica de Menezes Nogueira; Maria } \\
\text { Célia de Freitas. }\end{array}$ & Artigo Original & Enfermagem & $\begin{array}{l}\text { Descrever as características sociodemográficas e clínicas de } \\
\text { idosos institucionalizados. }\end{array}$ \\
\hline 2015 & $\begin{array}{l}\text { A Feminização da Velhice: em foco as } \\
\text { características } \\
\text { Socioeconômicas, pessoais e familiares das } \\
\text { idosas e o risco social. }\end{array}$ & $\begin{array}{l}\text { Alessandra Vieira Almeida } \\
\text { Simone Caldas Tavares Mafra; } \\
\text { Emília Pio da Silva; } \\
\text { Solange Kanso. }\end{array}$ & Artigo Original & $\begin{array}{l}\text { Serviço Social e } \\
\text { Economia } \\
\text { Doméstica }\end{array}$ & $\begin{array}{l}\text { Caracterizar o perfil socioeconômico, pessoal e familiar das } \\
\text { idosas do "Clube da Vovó", em Viçosa/MG, além de } \\
\text { identificar os tipos de riscos sociais enfrentados por elas } \\
\text { associados a esse perfil. }\end{array}$ \\
\hline 2015 & $\begin{array}{l}\text { Adequação da linguagem de enfermagem a } \\
\text { prática com idosos residentes em uma } \\
\text { instituição psiquiátrica de longa } \\
\text { permanência: mapeamento cruzado. }\end{array}$ & $\begin{array}{l}\text { Tatiana Gomes da Silva; Priscilla } \\
\text { Alfradique de Souza; Rosimere Ferreira } \\
\text { Santana. }\end{array}$ & Artigo Original & Enfermagem & $\begin{array}{l}\text { Mapear os termos livres dos registros de enfermagem e } \\
\text { comparar com a classificação de Diagnósticos de } \\
\text { Enfermagem. }\end{array}$ \\
\hline
\end{tabular}




\section{Discussão}

O estudo 1 contemplou nove idosos com afecção demencial, residentes em Instituição de Longa Permanência (ILPI), no interior baiano, onde ocorreu a sistematização de um modelo protocolar básico de cuidados de enfermagem fundamentado na taxonomia da North American Nursing Diagnosis Association (NANDA). Foi aplicado um Mini Exame do Estado Mental em duas fases, com espaço de seis meses, que sugeriram afecção demencial nestes idosos. Os dados foram angariados via instrumentos de estimativa multidimensional, disponibilizados pelo Ministério da Saúde. Fôra organizado um plano de cuidados, adotando os passos do processo de enfermagem, e agruparam-se os diagnósticos de enfermagem em quatro categorias, a saber: escala de comportamento motor, cognição e memória, comunicação e outros problemas físicos de saúde. Os planos de cuidado foram implementados e avaliados sucessivamente.

Já o estudo 2 contou com a participação de seis enfermeiros, onde aplicou-se um questionário tentando obter a identificação e a visão de enfermeiros sobre o cuidado de enfermagem direcionados aos idosos residentes em ILPIs. Mediante os dados coletados no estudo, o discurso do sujeito coletivo desencadeou as classes: Papel da ILPI na vida dos idosos e familiares; Desafios para o Brasil, a respeito do cuidado de enfermagem aos idosos residentes em ILPI; Cuidados de enfermagem imprescindíveis para os idosos institucionalizados; Realização de cuidados de enfermagem para os idosos residentes em ILPI; Organização do enfermeiro brasileiro para encarar adequadamente o cuidado de enfermagem aos idosos residentes em ILPI. Nestas categorias, considerou-se a preparação de cenários futuros para o ano 2026, ficando assim claro que o foco é a necessidade de preparo dos enfermeiros para cuidar de idosos institucionalizados, agora e em 2026.

No quinto estudo, foi abordada a senescência e a senilidade, temas cada vez mais debatidos considerando-se a crescente ampliação do número de idosos no mundo, principalmente no Brasil. O artigo ressaltou que o amparo ao idoso deve priorizar a conservação da qualidade de vida, ponderando o processo de perdas próprias do ciclo de vida e as possibilidades de prevenção, manutenção e reabilitação do seu estado de saúde. O estudo também expôs que avaliar o cotidiano dos idosos tem sido um desafio para os profissionais de saúde para implementar programas e ações que visem alcançar a manutenção do equilíbrio no processo saúde-doença, de fortalecimento dos idosos e seus familiares, de forma a tornar viável o desencadeamento de ações na promoção da saúde. Relatou também que o principal desafio para este milênio é edificar uma consciência coletiva para alcançar uma sociedade para todas as idades, com justiça e garantia plena de direitos.

O estudo 6 foi realizado com 24 idosas institucionalizadas em Fortaleza-CE, ele ocorreu durante o segundo semestre de 2009, ressaltou a identificação dos déficits de autocuidado de idosas institucionalizadas. Foi utilizado um roteiro de entrevista semiestruturada, com foco nos fatores 
condicionantes e nas condições para o autocuidado. Tendo como decorrência que os principais agentes que ocasionaram a institucionalização foram: a ausência de parentes para o cuidado, a indisponibilidade dos filhos para o provimento de cuidados, e a necessidade de viver em ambiente sem conflitos. Os déficits de autocuidado relacionavam-se aos seguintes fatores: hidratação, eliminação, sono e repouso, manutenção da saúde, interação social, autonomia, adaptação ao ambiente institucional e às alterações do ciclo vital da velhice, controle dos problemas crônicos de saúde. Ficando sob responsabilidade da equipe de enfermagem, estimular essas idosas a realizar o autocuidado.

Importante destacar que o estudo 7 relatou a experiência acadêmica de alunos de graduação em enfermagem, vivenciada na observação das altercações entre idosos ativos que participavam de um Grupo de Terceira Idade e idosos residentes numa Instituição de Longa Permanência. Foi identificado que a implementação de atividades desenvolvidas no Grupo de Terceira Idade permitiu ressignificações acerca do sentimento de abandono e exclusão dos idosos que, circunstancialmente encontram-se institucionalizados, dando assim, um aumento na perspectiva de qualidade de vida deste idoso.

O estudo 8 foi realizado com 7 mulheres, com idades entre 62 e 93 anos, todas residentes em uma instituição de longa permanência para idosos. Investigou os aspectos psicossociais do processo de institucionalização de mulheres idosas na cidade de Santo Antônio de Jesus, localizada na Bahia. Os dados foram avaliados através da análise de conteúdo temática. Ficando evidente que, para cinco das sete entrevistadas, a vida na instituição é relatada como boa, por encontrarem a satisfação das necessidades básicas do dia a dia como descanso e comida, neste estudo foi enfatizada a inexistência de programas voltados para o apoio a esta população.

Referente ao nono estudo, a pesquisa foi realizada com dez enfermeiros que atuavam em Unidades de Atenção Primária à Saúde, entrevistados entre setembro de 2010 e janeiro de 2011 e, mostrou a compreensão da ação de cuidar da mulher idosa, sob a visão do enfermeiro. Ressaltou que o enfermeiro pondera, para a efetivação do cuidado, a "bagagem" de conhecimentos e a "conjuntura biográfica" da mulher idosa, estimando a participação da família como mediadora do cuidado.

No estudo 10, houve a participação de 10 idosos asilados, o mesmo ocorreu no período de maio a junho de 2011, em uma instituição de longa permanência para idosos, no município de Maringá, por meio de entrevista semiestruturada, onde se buscou conhecer a percepção do idoso sobre os motivos que levaram à sua institucionalização, bem como seus sentimentos diante desta condição. Ficou evidente que os conflitos familiares e o fato de não ter família constituída foram os principais agentes preditores para a inserção dos idosos em ambiente asilar, e que esta condição pode despertar a sensação de sentimentos tidos negativos (solidão, angústia, ausência de liberdade e autonomia, dentre outros) e positivos (segurança de moradia, protagonismo social e bem-estar).

O estudo 11 objetivou interpretar o significado atribuído pelos idosos à vivência em uma Instituição de Longa Permanência para Idosos, do município de Curitiba, Paraná. O estudo foi realizado 
por meio das observações e entrevista etnográfica com os participantes (idosos), em uma instituição com fins lucrativos, durante janeiro a agosto de 2010. Insurgiram os seguintes domínios culturais: motivos que levaram a viver na instituição; maneiras de viver: atividades do cotidiano; atividades promovidas pela instituição; sentimentos atribuídos à vivência; características da instituição; e características das pessoas residentes; também, tema cultural: em busca do néctar da vida. Esta vivência significou para os idosos a possibilidade de poder ser cuidado e compreendido de forma abrangente, estes, relacionados como adstringentes à manutenção da vida e otimização do bem-estar, implicando em ações de cuidados em enfermagem.

No estudo 12, objetivou-se a ampliação da identificação de qualidade de vida aos idosos institucionalizados, também, a importância da equipe multidisciplinar junto às ILPIs. Foram utilizados como fonte de dados, bibliografias em livros e artigos científicos. Tendo as questões abordadas: envelhecimento populacional; instituições de longa permanência para idosos; a importância da equipe multidisciplinar e o papel desempenhado por ela. Ficou nítido que a união multidisciplinar desempenha um importante papel na vida dos residentes e da sociedade.

Já no estudo 13, foram entrevistados 34 idosos residentes em ILPIs, o mesmo descreve a percepção de idosos institucionalizados sobre as ações do psicólogo no local. O estudo ocorreu nas instituições cuidadoras e cadastradas no Conselho Municipal do Idoso. No estudo é revelado os atributos do psicólogo, considerados relevantes e pertinentes. Não foram percebidos pontos negativos desta específica práxis nas ILPIs. Constatou-se ainda que as áreas de atuação psicológica mais apontadas foram aquelas relacionadas à prevenção, diagnóstico e tratamento dos residentes naqueles locais.

O estudo 17 é uma revisão integrativa da literatura científica referente aos fatores que levam os idosos a saírem de seu ambiente familiar para residir em uma instituição de longa permanência para idosos (ILPI), também são levadas em consideração suas condições de vida e saúde. A análise foi realizada em14 artigos nas bases SciELO e LILACS (2001-2011). No estudo é descrito que as condições de vida e saúde dos idosos residentes em ILPIs alternavam entre independência, dependência parcial e dependência total para realização das atividades de vida diária. Outro ponto importante é a necessidade de mudança na orientação da assistência oferecida a esse grupo, além de aprimoramento na qualificação de cuidadores e trabalho em equipe multiprofissional, a fim de favorecer a qualidade de vida dos idosos que vivem nas ILPI.

O estudo 18 ocorreu com 18 graduandos de enfermagem de uma universidade pública de Salvador/Bahia, entre agosto e setembro de 2011, teve a finalidade de analisar a percepção dos graduandos de enfermagem sobre o envelhecimento. Os testemunhos dos discentes, obtidos por entrevistas, foram analisados por meio da análise de conteúdo temático. O núcleo temático foi: A visão do graduando sobre o envelhecimento, com as suas concernentes subcategorias- 1-Aprendizado e amadurecimento adquirido; 2-O estigma e a visão do velho e do novo; 3-Os sentimentos, limitações e 
perdas no processo de envelhecimento; 4-A proximidade da morte. Neste estudo é relatado que o envelhecimento consiste em um processo natural do ciclo vital, aceito como mais uma fase do desenvolvimento humano, conectado a mudanças biológicas, psicológicas, genéticas e ambientais, acompanhada da maturidade e da aprendizagem. Os aspectos negativos também foram citados, estes foram representados pelas classes perdas, limitações, incapacidades, finitude e proximidade da morte.

\section{Considerações Finais}

Através deste estudo, constatou-se reduzido número de pesquisas nacionais considerando-se a práxis do enfermeiro e do psicólogo conjuntamente, na assistência à saúde do idoso residente em ILPI, todavia, os trabalhos publicados na temática mostram-se inovadores. Verifica-se vasta discussão na literatura principalmente com enfoque na assistência prestada pela enfermagem, sobressaindo-se às discussões da assistência prestada pela psicologia a esse público.

A investigação, como fundamento para propostas de inovação no campo da Gerontologia, não pode deixar de ser conduzida. Os resultados dos estudos, a experiência de outros países já desenvolvidos e há mais tempo com a atual pirâmide etária, podem não somente servir de alicerce para alterações nos serviços, qualificação de pessoal, mas, também, para o aceno acerca de novos aspectos a serem introduzidos nos currículos das graduações de cursos de saúde, nos programas de residência e de formação permanente, por exemplo.

Neste sentido, realizar mais pesquisas nesta seara, considerando também as publicações internacionais se faz premente, uma vez que poderão promover um amplo fortalecimento nas opiniões, nas problematizações e nas críticas sobre o tema em questão. Deste modo, espera-se que este estudo sirva para subsidiar novas discussões acerca do cenário brasileiro sobre a práxis do enfermeiro e do psicólogo na assistência à saúde do idoso residente em Instituição de Longa Permanência para Idosos.

\section{Referências}

1. Oliveira ALB, Dourado MB, Menezes TMO. A percepção dos graduandos de enfermagem sobre envelhecimento. Rev enferm UERJ. 2014 set/out; 22(5):680-5. Rio de Janeiro (RJ), Brasil. 
2. Santana IO, Coutinho MPL, Ramos N, Santos DS, Lemos GLC, Silva PB. Mulher Idosa: Vivências do processo de institucionalização. ex aequo.2012; 26:71-85. Brasil.

3. IBGE-Instituto Brasileiro de Geografia e Estatística: Síntese de Indicadores Sociais Uma análise das condições de vida da população brasileira 2013. Rio de Janeiro (RJ), Brasil; 2013.

4. IBGE-Instituto Brasileiro de Geografia e Estatística: Tendências demográficas no período de 19402000. Rio de Janeiro (RJ), Brasil; 2010.

5. Nicodemo D, Godoi M P. Juventude dos anos 60-70 e envelhecimento: estudo de casos sobre feminização e direitos de mulheres idosas. Rev Ciênc em Extensão. 2010; 6(10). Brasil.

6. Rissardo LK, Furlan MCR, Grandizolli G, Marcon SS, Carreira L. Sentimentos de residir em uma instituição de longa Permanência: percepção de idosos asilados. Rev. enferm. UERJ, 2012 jul/set; 20(3):380-5.Rio de Janeiro.

7. Camarano AA. Cuidados de longa duração para a população idosa: um novo risco social a ser assumido? Ipea. 2010; Rio de Janeiro (RJ), Brasil.

8. Camargo RCVF. Implicações na saúde mental de cuidadores de idosos: uma necessidade urgente de apoio formal. Rev Elet Saúde Ment Álcool e Drogas. 2010; 6(2). Brasil.

9. Cardoso LS, Silva BT, Rodrigues DS, Leal CL, Penner MCS. Pessoa idosa: capacidade funcional para as atividades básicas e instrumentais da vida diária. J. revista: fundam. care. online. 2014 abr./jun; 6(2):584-593. Brasil.

10. Araújo CLO, Lopes CM, Santos GR, Junqueira LP. Perfil dos colaboradores de uma Instituição de Longa Permanência para Idosos (ILPI). Rev Kairós Geront. 2014 março; 17(1): 219-230. São Paulo (SP), Brasil.

11. Moreira MADM, Lustosa AM, Dutra F, Barros EO, Batista JBV, Duarte CS. Políticas públicas de humanização: revisão integrativa da literatura. Ciênc \& Saúde Col. 2015.; 20(10):3231-3242. Brasil.

12. Silva BCO, Carvalho GRP, Carvalho IS, Neto AVL, Nunes VMA, Araújo RDT. Experiências vivenciadas por acadêmicos de enfermagem com idosos institucionalizados e não institucionalizados. Rev Kairós Geront. 2012 jun; 15(3):179-189.São Paulo (SP), Brasil.

13. BRASIL. (2005). Resolução RDC $n .^{\circ} 283$ de 26 de setembro de 2005. Aprova o Regulamento Técnico que define normas de funcionamento para as Instituições de Longa Permanência para Idosos. Diário Oficial da República Federativa do Brasil, Brasília (DF), 26 set. 2005 Seção 1: 58.

14. BRASIL. (2006). Portaria GM/MS n. ${ }^{\circ} 2.528$, de 19 de outubro de 2006. Aprova a Política Nacional de Saúde da Pessoa Idosa. Diário Oficial da República Federativa do Brasil, Brasília (DF), 20 out. 2006 Seção 1: $142 . \quad$ Disponível em: http://bvsms.saude.gov.br/bvs/saudelegis/gm/2006/prt2528 19 10 2006.html.

15. Freitas MC, Guedes MVC, Galiza FT, Nogueira JM, Onofre MR. Idosos residentes em uma instituição de longa permanência: adaptação à luz de Callista Roy. Rev Bras Enferm. 2014 novdez; 67(6):905-12. Brasil. 
16. Almeida AV, Mafra SCT, Silva EP, KANSO S. A Feminização da Velhice: em foco as características socioeconômicas, pessoais e familiares das idosas e o risco social. Textos \& Contextos. 2015 jan./jun; v. 14, n. 1, p. 115 - 131, 2015 Porto Alegre, Brasil.

17. Silva JDA, Comin FS, Santos MA. Idosos em Instituições de Longa Permanência:

Desenvolvimento, Condições de Vida e Saúde. Psicologia: Reflexão e Crítica, 2013; 26(4), 820830. Brasil.

18. Cocco AR, Naspoloni AP, Grando FP, Volgoi N, Silva E, Medeiros PA, et al. A imobilidade em Instituição de Longa Permanência: Compreendendo o desafio vivenciado pelas equipes de saúde. Rev Kairós Geront. 2013 junho; 16(3): 263-284. São Paulo (SP), Brasil.

19. Jesus IS, Sena ELS, Meira EC, Gonçalves LHT, Alvarez AM. Cuidado sistematizado a idosos com afecção demencial residentes em instituição de longa permanência. Rev Gaúcha Enferm. 2010 jun; 31(2):285-92. Porto Alegre (RS), Brasil.

20. Gorzoni ML, Pires SL. Óbitos em instituição asilar. Rev Assoc Med Bras. 2011; 57(3):333-337. Brasil.

21. Frota NM, Santos ZMSA, Soares E, Moura JMG, Costa AC, Caetano JÁ. Déficits de autocuidado de idosas institucionalizadas. Rev Rene. 2012 maio; 13(5):983-94. Brasil.

22. Oliveira JM, Rozendo CA. Instituição de longa permanência para idosos: um lugar de cuidado para quem não tem opção?. Rev Bras Enferm. 2014 set/out; 67(5):773-9. Brasil.

23. Borges CL, Silva MJ, Clares JWB, Nogueira JM, Freitas MC. Características sociodemográficas e clínicas de idosos institucionalizados: contribuições para o cuidado de enfermagem. Rev enferm UERJ. 2015 mai/jun; 23(3):381-7. Rio de Janeiro, Brasil. Disponível em: http://www.facenf.uerj.br/v23n3/v23n3a15.pdf.

24. Silva BT, Santos SSC. Cuidados aos idosos institucionalizados - opiniões do sujeito coletivo enfermeiro para 2026. Acta Paul Enferm. 2010; 23(6):775-81. Brasil.

25. Oliveira PB, Tavares DMS. Condições de saúde de idosos residentes em Instituição de Longa Permanência segundo necessidades humanas básicas. Rev Bras Enferm. 2014 mar-abr; 67(2):2416. Brasil.

26. Sousa L, Ribeiro AP. Prestar cuidados de enfermagem a pessoas idosas: experiências e impactos. Saúde Soc. São Paulo. 2013; v.22, n.3, p.866-877. Brasil.

27. Silva TG, Souza PA, Santana RF. Adequação da linguagem de enfermagem a prática com idosos residentes em uma instituição psiquiátrica de longa permanência: mapeamento cruzado. Revista de pesquisa Cuidado é fundamental Oline. 2015 out/dez; 7(4): 3467-3478. Brasil.

28. Michel T, Lenardt M.H, Betiolli S.E, Neu DKM. Significado atribuído pelos idosos à vivência em uma Instituição de longa permanência: contribuições para o cuidado de enfermagem. Texto \& Contexto Enfermagem. 2012 jul/set; vol. 21, núm. 3pp. 495-504

Universidade Federal de Santa Catarina Santa Catarina, Brasil.

29. Rocha MDM, Ribeiro MCP. Projeto saúde do idoso institucionalizado atuação dos profissionais na atenção à saúde de idosos residentes em instituição de longa permanência. Revista da Universidade Vale do Rio Verde. 2011jan-jul; 9(1):152-172. Três Corações, Brasil. 
30. Corrêa JC, Ferreira MEC, Ferreira VN, Banhato EFC. Percepção de idosos sobre o papel do Psicólogo em Instituições de Longa Permanência. Rev. Bras. Geriatr. Gerontol. 2012 15(1):127136. Rio de Janeiro, Brasil.

31. Costa MCNS, Mercadante EF. O Idoso residente em ILPI (Instituição de Longa Permanência do Idoso) e o que isso representa para o sujeito idoso. Revista Kairós Gerontologia. 2013 março; 16(2), 209-222. São Paulo (SP), Brasil.

32. Ciosak SI, Braz E, Costam MFBNA, Nakano NGR, Rodrigues J, Alencar RA,et al. Senescência e senilidade: novo paradigma na Atenção Básica de Saúde. Rev Esc Enferm. 2011. Brasil. Disponível em: http://www.scielo.br/pdf/reeusp/v45nspe2/22.pdf.

33. Caldeira S, Merighi MAB, Muñoz LA, Jesus MCP, Domingos SRF, Oliveira DM. O enfermeiro e o cuidado à mulher idosa: abordagem da fenomenologia social. Rev. Latino-Am. Enfermagem. 2012 set.-out; 20(5). Brasil. Disponível em: http://www.scielo.br/pdf/rlae/v20n5/pt 10.pdf.

34. Ghandour A, Padovani RC, Batistoni SST. Habilidades de resolução de problemas e indicadores de bem-estar emocional em profissionais de enfermagem que atuam em Instituições de Longa Permanência para Idosos. Rev Kairós Geront. 2014 junho; 17(2):239-255. São Paulo (SP), Brasil.

\section{Como citar este artigo (Formato ABNT):}

MONTEIRO, Andreane Natália P. de Almeida; PEREIRA, Juliane da Silva; VALENÇA, Mércia Alcântara Feitosa; BATISTA, Maria Amanda Lima; BARBOSA, Luciclaudio da Silva; SANTOS, Silvana Cavalcanti dos; ALEXANDRE, Ana Carla Silva; LEITE-SALGUEIRO, Claudia Daniele Barros. Estudos Nacionais Sobre as Assistências de Enfermagem e de Psicologia ao Idoso Residente em Instituição de Longa Permanência. Id on Line Rev.Mult. Psic., 2018, vol.12, n.41, p.1048-1054. ISSN: 1981-1179.

Recebido: 11/07/2018.

Aceito: 26/07/2018 